\title{
Co-firing of blends of sugarcane bagasse and coal
}

\author{
Thermal and kinetic behaviors
}

\author{
Daniela A. Mortari ${ }^{1} \cdot$ Lilian D. M. Torquato $^{2} \cdot$ Marisa S. Crespi $^{2} \cdot$ Paula M. Crnkovic $^{1}$
}

Received: 24 April 2017 / Accepted: 15 January 2018/ Published online: 2 February 2018

(C) Akadémiai Kiadó, Budapest, Hungary 2018

\begin{abstract}
The interaction effects between sugarcane bagasse and a Brazilian coal during co-firing were investigated by means of thermal decomposition behavior, comparison between theoretical and experimental results, activation energy, and ignition temperature. The blends were prepared in the ratios of 100:0; 75:25; 50:50; 25:75; 0:100 (bagasse/coal). The interaction effect evaluated in this study was related to the interference of the bagasse volatile matter content in the coal thermal decomposition. The thermal decomposition behavior analyses were performed in a thermogravimetric balance, and the apparent activation energy was determined by two different models-model-free and local linear integral isoconversional method-under two different heating rate ranges. The results showed that the high volatile content of the sugarcane bagasse leads to more intense combustion, lower ignition temperature, and more complex reaction mechanism, as compared to coal. When the fuels are blended, there is a temperature anticipation of the events related to the decomposition of the coal portion in the mixture, the reaction rates increase and the ash formation is affected. The kinetic data also suggested that the interaction between both materials may occur and improve the burnout of the blend in relation to the pure coal firing due to the contribution of sugarcane bagasse volatile matter. Nevertheless, the presence of the bagasse did not allow to lower activation energy during the blends devolatilization process.
\end{abstract}

Keywords Co-firing $\cdot$ Sugarcane bagasse $\cdot$ Coal $\cdot$ Thermal decomposition $\cdot$ Activation energy $\cdot$ Ignition temperature

\section{Introduction}

There are several government programs encouraging the use of renewable fuels. New forms for supplying the energy demand should be safe, environmentally friendly, and affordable. However, the use of pure biomass firing in some industrial processes is still unattractive due to its low bulk density, high moisture content, and low calorific value. In addition, pure biomass firing is not economically feasible due to limitations of the existing technologies [1-3].

Daniela A. Mortari

daniela.mortari@usp.br

1 School of Engineering of São Carlos, University of São Paulo (USP), São Carlos CEP 13566-590, Brazil

2 Department of Analytical Chemistry, Institute of Chemistry of Araraquara, UNESP - São Paulo State University, Araraquara, SP 14801-970, Brazil
Co-firing biomass with coal is a subject of great interest worldwide and represents an alternative technology to reduce greenhouse gas emissions, including sulfur oxides $\left(\mathrm{SO}_{x}\right)$ and nitrogen oxides $\left(\mathrm{NO}_{x}\right)$. It can also be implemented in existing coal-fired power plants, resulting in reduced capital investment [4].

According to [4], more than 230 coal-generating stations have operated or experienced biomass co-firing activities [4]. However, due to the differences in composition with biomass and coal, as well as the wide variety of each one, it is critical to study the thermal and kinetic behaviors of such mixtures.

Among the most used biomasses in the world, sugarcane bagasse deserves great attention, as it is grown in more than 100 countries according to [5]. In this context, Brazil presents a promising scenario, being the largest producer of sugarcane and, consequently, the largest producer of sugarcane bagasse (632.127 million tons in 2014/2015) [6]. 
Moreover, South Brazil encompasses large coal reserves estimated to be $10^{6}$ tons [7].

The knowledge regarding biomass characteristics and their blends with other fuels is essential to design, operate and model industrial conversion systems such as furnaces and boilers [8]. In addition, the knowledge of the thermal decomposition of the biomass-either pure or blended with coals-is important for the development of efficient technological processes [9].

Thermal evaluation of biomass and coal via thermogravimetric analysis (TGA) and differential thermal analysis (DTA) has been extensively used to study interactions during solid-phase thermal decomposition. TGA allows the rapid assessment of thermal and kinetic behaviors and is a suitable tool for initial screenings. It is a well-established technique used by many to study the interaction between fuels using [10-13]. Kinetic analysis has become a crucial assessment in thermal analysis, since it can provide a good prediction of process rates, material lifetimes, and an interpretation of the energy barriers and reaction mechanisms [14, 15]. Kinetic parameters can be calculated from TGA data by using model fitting or model-free methods [16]. Several kinetic models have been described in the literature, and the most commonly reported methods are Kissinger, Friedman, Flynn-Wall-Ozawa and Coast and Redfern, model-free kinetic, among others [10, 14, 16].

Biomass has higher thermochemical reactivity over coal, due to higher volatile matter content and hydrogen/carbon molar ratio (H/C). As a consequence, synergistic effects can occur when biomass is blended with coal $[17,18]$. Investigating these effects is of great importance to enable the large scale application of blend co-firing. Important of notice is that operational parameters such as heating rate and sample amount might affect the investigation of interaction effects [19].

The occurrence of synergism in blend co-firing is a subject that generates conflicting results, especially considering the difference of experimental conditions applied by different authors [16]. For instance, Bragato et al. [19] conducted experiments in a preheated laboratory-scale electric horizontal furnace and reported a reduction in emissions when bagasse is blended with coal. Krerkkainwan et al. [20] also observed the occurrence of a synergetic effect between biomass and coal in experiments performed in a drop tube fixed-bed reactor, especially for a blending ratio of $1: 1(\mathrm{w} / \mathrm{w})$.

Nevertheless, Kastanaki et al. [21] investigated the devolatilization behavior and the kinetics of biomass/lignite blends in a thermogravimetric analyzer and no substantial interactions between both solids fuels were observed. Idris et al. [22] conducted experiments in a thermogravimetric analyzer and concluded that biomass/coal blends seem to undergo an independent thermal degradation without any interaction effect. Sahu et al. [23] suggested that the devolatilization behavior of this type of blends is additive.

Although several studies have reported that biomass/coal blends under thermal processes may or may not present interaction effects, it is important to evaluate these interactions as a function of parameters such as blending ratio and heating rate. Various explanations based on transport and/or heat transfer limitations were used to interpret apparent discrepancies reported in the literature [24]. The improvement in coal decomposition when blend with biomass was attributed to the transference of $\mathrm{OH}$ and $\mathrm{H}$ formed from the biomass pyrolysis [19]. Potassium from the biomass appeared to promote significant catalytic effect during co-firing with coal.

The interaction activity between biomass and coal and the mechanisms of such reactions is still not well understood. Hence, the present work aims to evaluate the thermal and kinetic behaviors of blends of sugarcane bagasse and coal. Interactions of different ratio blends were evaluated for thermal decomposition, activation energy, comparison of theoretical and experimental TG curves, and ignition temperature. In this study, two kinetic models were applied to better evaluate the effects on reactivity during the blends combustion. In addition, the ignition temperature analysis was performed to investigate the influence of volatile matter on the blends decomposition.

\section{Experimental}

\section{Solid fuels}

Bituminous coal (CE4500) from Criciúma-SC, South region of Brazil, and sugarcane bagasse from the central region of São Paulo State (Brazil) were used. Prior to thermogravimetric experiments, samples were crushed and sieved to compose the average grain size range of $89.5 \mu \mathrm{m}$, i.e., the fraction chosen for this work was that obtained from the sieves 105 and $74 \mu \mathrm{m}$. Before being crushed, bagasse was washed in water during $5 \mathrm{~min}$ to remove all soil residues and dried in oven at $80{ }^{\circ} \mathrm{C}$ for $24 \mathrm{~h}$.

Samples were analyzed pure and blended in the following ratios: $100 \%$ bagasse/0 coal (100:0); 75\% bagasse/ $25 \%$ coal $(75: 25) ; 50 \%$ bagasse $/ 50 \%$ coal $(50: 50) ; 25 \%$ bagasse $/ 75 \%$ coal (25:75); and 0 bagasse/100\% coal $(0: 100)$. The efficiency of each blend was verified by TG, ash percentage, volatile matter, and fixed carbon. Tables 1 and 2 show the chemical composition and porosity characteristics of each solid fuels. Figure 1 presents their morphological structures obtained by scanning electron microscopy (SEM). 
Table 1 Chemical composition of coal and sugarcane bagasse (dry basis)

\begin{tabular}{lcc}
\hline Properties & \multicolumn{2}{l}{ Sample } \\
\cline { 2 - 3 } & CE 4500 & Sugarcane bagasse \\
\hline Proximate analysis/wt\% & & \\
Moisture & 1.2 & 4.4 \\
Volatile matter & 23.1 & 83.9 \\
Fixed carbon & 24.5 & 7.7 \\
Ash & 51.2 & 4.0 \\
Ultimate analysis/wt\% & & \\
Carbon & 54.9 & 44.3 \\
Hydrogen & 3.6 & 5.7 \\
Oxygen & & 45.5 \\
Nitrogen & 7.92 & 0.2 \\
Sulfur & 1.1 & 0.07 \\
\hline
\end{tabular}

${ }^{a}$ By Ávila et al. [25]

${ }^{\mathrm{b}}$ Calculated by difference

\section{Methodology}

Interaction effects (synergism) between sugarcane bagasse and coal were evaluated (a) by comparing the experimental and theoretical TG/DTG curves, (b) by evaluating the activation energy versus conversion profiles (DTG curves) under low heating rates $\left(2.5,5,10^{\circ} \mathrm{C} \mathrm{min}{ }^{-1}\right)$ and also under high heating rates $\left(20,25\right.$, and $\left.30^{\circ} \mathrm{C} \mathrm{min}{ }^{-1}\right)$, and (c) by comparing the ignition temperatures.

For the evaluation of the thermal behavior and ignition temperature, experiments were carried out in a Shimadzu TGA-51 analyzer with the following conditions: sample mass of $7.0 \pm 0.5 \mathrm{mg}$, alumina sample holder, and temperature ranging from 25 to $700{ }^{\circ} \mathrm{C}$. The thermal behavior was also evaluated by means of DTA experiments under air atmosphere and heating rate of $20{ }^{\circ} \mathrm{C} \mathrm{min}^{-1}$.

The ignition temperature was calculated based on Tognotti methodology [26] by comparing the TG curves in air and nitrogen $\left(100 \mathrm{~mL} \mathrm{~min}^{-1}\right)$ — both obtained for a heating rate of $10{ }^{\circ} \mathrm{C} \min ^{-1}$. According to this methodology, the ignition temperature is the intersection point between both curves, where volatile matter devolatilization takes place.

The thermal behavior evaluation was performed by applying the same heating rates used during kinetic study: $2.5,5,10,20,25$, and $30{ }^{\circ} \mathrm{C} \mathrm{min}{ }^{-1}$. However, here we report heating rate of $20{ }^{\circ} \mathrm{C} \mathrm{min}{ }^{-1}$ because it is an intermediate ratio and the curves performed under this condition present more information about the process than the curve performed under $10{ }^{\circ} \mathrm{C} \mathrm{min}^{-1}$.

To simulate oxidation conditions, all experiments were performed under synthetic air flow $\left(100 \mathrm{~mL} \mathrm{~min}^{-1}\right)$.

Theoretical curves were calculated based on the average values of the experimental TG and DTG curves of individual blend components according to their ratio in the blend. The additive rule for the blend 25:75 is as follows:

$\frac{d_{\mathrm{m}}}{d_{\mathrm{t}}}($ mixture $)=0.75\left(\frac{d_{\mathrm{m}}}{d_{\mathrm{t}}}\right)_{\text {coal }}+0.25\left(\frac{d_{\mathrm{m}}}{d_{\mathrm{t}}}\right)_{\text {bagasse }}$

where $m$ is the mass obtained from the TG curve.

Kinetic parameters were obtained in a simultaneous TGA-DTA thermal analyzer (Model SDT 2960, TA Instruments), with an inert $\alpha$-alumina sample holder. Prior to the experiments, the equipment was calibrated for each heating rate $\left(2.5,5,10,20,25\right.$, and $\left.30{ }^{\circ} \mathrm{C} \mathrm{min}-1\right)$. It was verified that the flow rate of $100 \mathrm{~mL} \mathrm{~min}^{-1}$ is the most
Table 2 Physical characteristics of coal and sugarcane bagasse

\begin{tabular}{llll}
\hline Sample & $S_{\mathrm{P}} / \mathrm{m}^{2} \mathrm{~g}^{-1}-\mathrm{BET}$ & $V_{\text {P.ds }} / \mathrm{cm}^{3} \mathrm{~g}^{-1}-\mathrm{BJH}$ & $D_{\text {P.ds }} / \AA-\mathrm{AJH}$ \\
\hline CE 4500 & 2.787 & 0.014 & 156.808 \\
Sugarcane bagasse & 0.981 & 0.005 & 201.089 \\
\hline
\end{tabular}

$\mathrm{S}_{\mathrm{P}}$, superficial area; $\mathrm{V}_{\mathrm{P} . \mathrm{ds}}$, pores volume in the desorption; $\mathrm{D}_{\mathrm{P} . \mathrm{ds}}$, pores diameter in the desorption
Fig. 1 Morphological structures of a sugarcane bagasse and b coal CE 4500. Images obtained by SEM, with magnitude of $\times 1000$

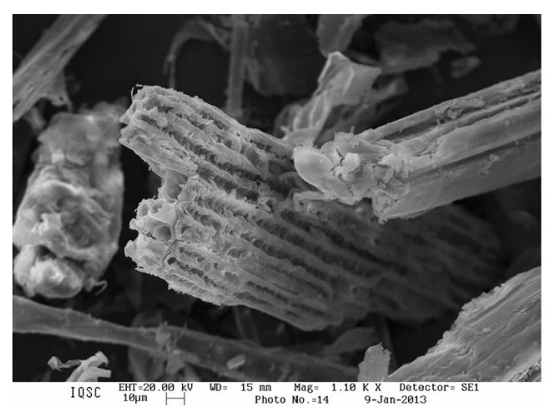

(a)

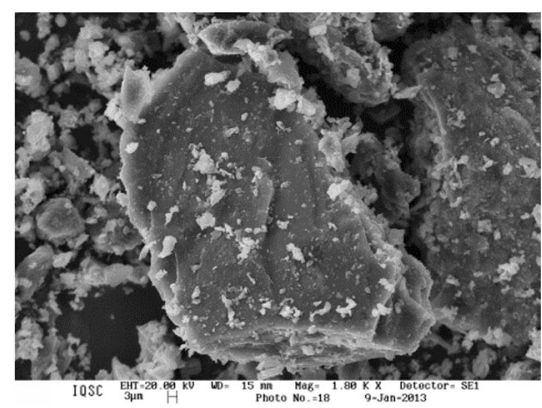

(b) 
suitable to perform the kinetic experiments as it did not cause diffusional limitations in the TG curves for the highest heating rate applied.

Kinetics evaluation was performed in order to determine the activation energies of the samples during the combustion process and to provide information about the energetic feasibility of the blends. In this study, activation energy was calculated considering the first step of decomposition, which is related to devolatilization. Decomposition temperature ranges applied for activation energy calculations are presented in Table 3.

The activation energy $\left(E_{\alpha}\right)$ was obtained for each sample applying two different models: model-free kinetic and the local linear integral isoconversional method (LLII).

The model-free kinetics model is based on the isoconversional equation of Arrhenius, which can be described as follows:

$k(T)=A \exp \left(\frac{-E_{\alpha}}{R T}\right)$

where $A$ and $E_{\alpha}$ are kinetic parameters (pre-exponential factor and activation energy, respectively), $R$ is the universal gas constant, and $k(T)$ is the temperature-dependent constant, which is related to the rate of conversion $(\mathrm{d} \alpha / \mathrm{d} t)$ and the reaction model $f(\alpha)$ according to:

$\frac{\mathrm{d} \alpha}{\mathrm{d} t}=k(T) f(\alpha)$

The conversion rate $(\alpha)$ is defined as:

$\alpha=\frac{m_{0}-m_{\mathrm{t}}}{m_{0}-m_{\mathrm{f}}}$

where $m_{0}$ is the initial mass, $m_{\mathrm{f}}$ is the final mass, and $m_{\mathrm{t}}$ is the mass of the sample at time $(t)$.

The model-free kinetics requires the use of at least three TG curves with different heating rates $(\beta)$ by applying nonisothermal programs with linear temperature change. Combining Eqs. 2-4:

$\frac{\mathrm{d} \alpha}{\mathrm{d} T}=\frac{A}{\beta} \exp \left(\frac{-E_{\alpha}}{R T}\right) f(\alpha)$
Equation 5 is the fundamental expression to calculate the kinetic parameters from TGA data. The method modelfree kinetic used in this study is based on that proposed by Vyazovkin [27]:

$\ln \left(\frac{\beta}{T_{\alpha}^{2}}\right)=\ln \left[\frac{R A}{E_{\alpha} g(\alpha)}\right]-\left(\frac{E_{\alpha}}{R}\right) \frac{1}{T_{\alpha}}$

where $E_{\alpha}\left(\mathrm{kJ} \mathrm{mol}^{-1}\right)$ is the activation energy related to each conversion value $(\alpha), \beta$ is the heating rate $\left(\mathrm{K} \mathrm{min}^{-1}\right), T_{\alpha}$ is temperature (K), related to each $\alpha$ value, and $g(\alpha)$ is the integral form of the inverse function $f(\alpha)$, that is the model reaction. This isoconversional method directly leads to $\left(-E_{\alpha} / R\right)$ for a given value of $\alpha$ by plotting the $\ln \left(\beta / T_{\alpha}^{2}\right)$ against $1 / T_{\alpha}$.

The second kinetic method applied (LLII) is also a method free of model, which is based on the interactive theorem of integral average value, analogous to the proposed by Wanjun and Donghua [28].

This method was previously applied to evaluate the activation energy dependence in non-isothermal conditions of sugarcane bagasse and its blends with sludge [10] as well as of different kinds of wastes generated in sugarcane mills [29].

Considering the fundamental Eq. 5, parameters $E_{\alpha}, A$, and the local heating rate $\beta$ are assumed to be constant in a sufficiently short conversion range $[\alpha-\Delta \alpha, \alpha+\Delta \alpha]$, resulting in the function $g$, an integral form for kinetic model (Eq. 7):

$\Delta g(\alpha)=\int_{\alpha-\Delta \alpha}^{\alpha+\Delta \alpha} \frac{1}{f(\alpha)} \mathrm{d} \alpha=\frac{A}{\beta} \int_{T \alpha-\Delta \alpha}^{T \alpha+\Delta \alpha} \mathrm{e}^{-\frac{\mathrm{E}}{\mathrm{RT}}} \mathrm{d} T$

where $\Delta g(\alpha)=g(\alpha+\Delta \alpha)-g(\alpha-\Delta \alpha)$ e $g^{\prime}(\alpha)=1 / f(\alpha)$.

The linear relation (Eq. 8) is obtained by applying the mean value theorem to the integral in Eq. 7 and the Taylor series expansion around $\tau_{\alpha}$ in $\mathrm{e}^{-\frac{\mathrm{E} \alpha}{\mathrm{R} T_{\alpha}}}$ for $\tau_{\alpha}$ in the range $\left[T_{\alpha-\Delta \alpha}, T_{\alpha+\Delta \alpha}\right]$.

$\ln \left[\frac{\beta_{\alpha}}{\Delta T_{\alpha}(1+\gamma)}\right]=B_{\alpha} \mathrm{e}^{-\frac{\mathrm{E}_{\alpha}}{\mathrm{R} T_{\alpha}}}$

were $\beta_{\alpha}=\left[\frac{A_{\alpha}}{\Delta g(\alpha)}\right]$.
Table 3 Temperature decomposition range based on TG/DTG curves applied to calculate activation energy

\begin{tabular}{|c|c|c|c|c|c|c|c|c|c|c|}
\hline \multirow{2}{*}{$\begin{array}{l}\text { Bagasse/coal ratio } \\
\text { Heating rate } /{ }^{\circ} \mathrm{C} \min ^{-1}\end{array}$} & \multicolumn{2}{|l|}{$0: 100$} & \multicolumn{2}{|l|}{ 100:0 } & \multicolumn{2}{|l|}{$75: 25$} & \multicolumn{2}{|l|}{$50: 50$} & \multicolumn{2}{|l|}{$25: 75$} \\
\hline & $T_{1} /{ }^{\circ} \mathrm{C}$ & $T_{2} /{ }^{\circ} \mathrm{C}$ & $T_{1} /{ }^{\circ} \mathrm{C}$ & $T_{2} /{ }^{\circ} \mathrm{C}$ & $T_{1} /{ }^{\circ} \mathrm{C}$ & $T_{2} /{ }^{\circ} \mathrm{C}$ & $T_{1} /{ }^{\circ} \mathrm{C}$ & $T_{2} /{ }^{\circ} \mathrm{C}$ & $T_{1} /{ }^{\circ} \mathrm{C}$ & $T_{2} /{ }^{\circ} \mathrm{C}$ \\
\hline 2.5 & 262 & 551 & 190 & 355 & 175 & 346 & 195 & 336 & 208 & 329 \\
\hline 5 & 285 & 579 & 190 & 357 & 184 & 356 & 190 & 353 & 209 & 343 \\
\hline 10 & 296 & 611 & 205 & 372 & 200 & 368 & 204 & 364 & 211 & 357 \\
\hline 20 & 313 & 645 & 211 & 373 & 201 & 378 & 207 & 370 & 214 & 370 \\
\hline 25 & 322 & 668 & 213 & 376 & 209 & 375 & 218 & 379 & 230 & 375 \\
\hline 30 & 331 & 676 & 221 & 380 & 226 & 380 & 206 & 385 & 214 & 376 \\
\hline
\end{tabular}


For each value of $\alpha$, in a series of $n \geq 3$ non-isothermal experiments carried out at heating rates, $\left(\beta_{\alpha, i}, i=1,2, \ldots n\right)$, Eq. (8) can be used to develop a linear iterative isoconversional method to estimate $E_{\alpha}$ and $\beta_{\alpha}$, which was performed with the free Software $\mathrm{R}^{\circledR}, 3.2 .1$ version, using the mathematical procedures previously programmed.

\section{Results and discussion}

\section{Thermogravimetric results}

Figure 2 shows the TG and DTG curves for different ratios of sugarcane bagasse and coal at heating rate of $20{ }^{\circ} \mathrm{C} \min ^{-1}$.

For pure sugarcane bagasse (100:0), the mass loss occurs in three events. The first one is related to moisture loss, which occurs between 30 and $100{ }^{\circ} \mathrm{C}$. Above $200{ }^{\circ} \mathrm{C}$, the following two events of mass loss are characteristic of lignocellulosic materials decomposition. Between 200 and $360{ }^{\circ} \mathrm{C}$, the decomposition events are related to hemicellulose and cellulose decomposition, which leads to the production of volatiles [30-35].

As can be observed in Fig. 2b, these events overlap and can be distinguished by means of an inflection change on DTG curve at around $315^{\circ} \mathrm{C}$, highlighted with the arrows. The lignin decomposition occurs between 170 and $550{ }^{\circ} \mathrm{C}$, and the peak is observed at around $460{ }^{\circ} \mathrm{C}$ in Fig. $2 \mathrm{~b}$.

For coal (0:100), thermal degradation process starts at $320^{\circ} \mathrm{C}$, with an initial mass gain arising from the chemisorption of oxygen on coal surface, which will cause the thermal decomposition to happen in increasing temperature [36-38] The events of mass loss related to volatile matter combustion (primary combustion) and the char combustion (secondary combustion) are not clearly distinguished (Fig. 2a). However, DTG curve (Fig. 2b) shows a double peak (between 330 and $640{ }^{\circ} \mathrm{C}$ ) related to this event.

For the blends, the events of mass loss occur in intermediate range of temperature and proportionally to the ratio of components in mixture. It is interesting to note that between 200 and $600{ }^{\circ} \mathrm{C}$ there are two main events of decomposition. The first one starts around $240{ }^{\circ} \mathrm{C}$, which is close to the initial decomposition of the neat bagasse. The second event occurs at around $450{ }^{\circ} \mathrm{C}$, which is possibly related to the beginning of coal thermal decomposition.

It can be observed, by the DTG curves, that the maximum reaction rates of bagasse sample occur between 220 and $360{ }^{\circ} \mathrm{C}$ and for coals, above $450{ }^{\circ} \mathrm{C}$.

The maximum reaction rates during thermal decomposition of the biomass at low temperature are attributed to the heat released due to volatile matter decomposition. On the other hand, the maximum reaction rates of coals at higher temperature are due to the char combustion, since this material has a lower volatile matter content [39]. Therefore, bagasse is more prompt to ignite and burn at lower temperatures with a higher reaction rate when compared to coal.

Figure 3 shows the DTA curves related to the thermal decomposition of pure and blended samples under heating rate of $20^{\circ} \mathrm{C} \min ^{-1}$. DTA curves show the sum of the heat involved in the thermal processes. It is possible to observe two exothermic events happening above $110{ }^{\circ} \mathrm{C}$. Only the first event related to moisture evaporation is a negative summation (endothermic event).

Similar results are presented in the literature. Da Silva et al. [40] reported that during the sugarcane bagasse thermal decomposition (atmospheric air, $150{ }^{\circ} \mathrm{C}$ ), there is an endothermic event related to moisture loss, then two

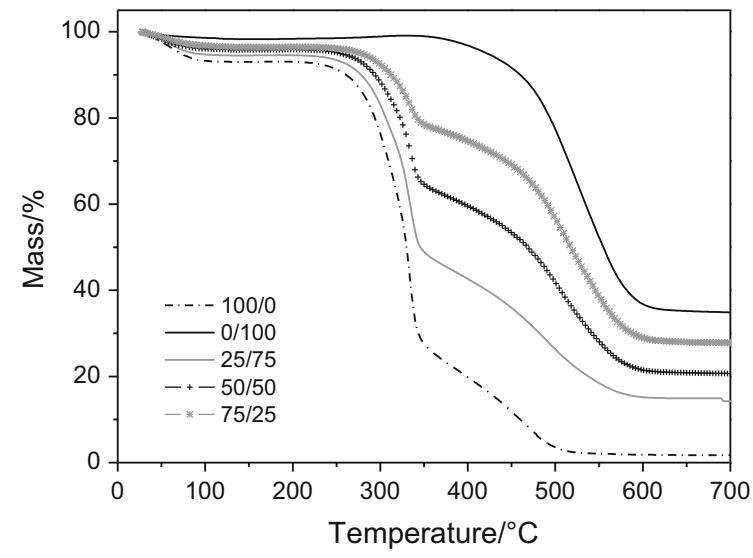

(a)

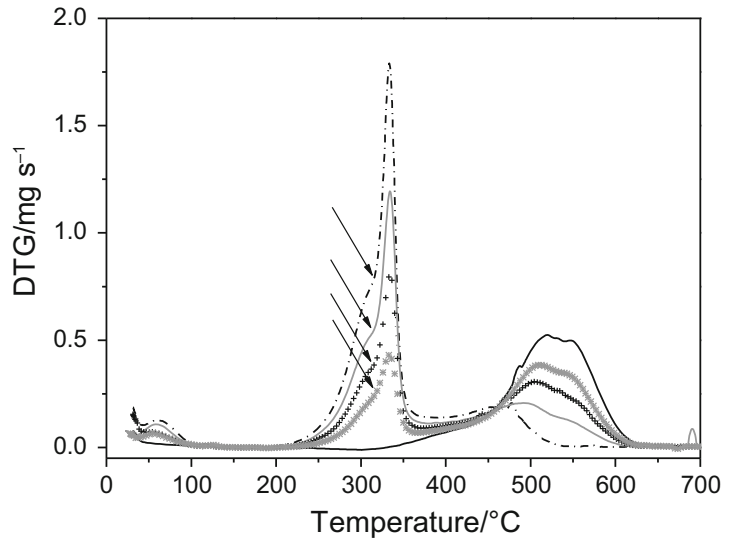

(b)

Fig. 2 TG (a) and DTG (b) curves for different blends performed under synthetic air atmosphere $\left(100 \mathrm{~mL} \mathrm{~min}^{-1}\right)$ and heating rate of $20{ }^{\circ} \mathrm{C} \min ^{-1}$ 
exothermic events: one between 180 and $430{ }^{\circ} \mathrm{C}$ related to oxidation of cellulose and hemicellulose and, another between 430 and above $600{ }^{\circ} \mathrm{C}$ related to oxidation of lignin and carbonaceous residue. The authors also reported a displacement of the exothermic shoulder to lower temperatures when fuels are blended (bagasse + vinasse). The original vinasse sample shows a peak that ends above $600{ }^{\circ} \mathrm{C}$. After blending, the maximum peak intensity is displaced to temperatures between 460 and $505{ }^{\circ} \mathrm{C}$ [40]. El-Sayed and Mostafa [15] also reported two exothermic peaks in DTA curves during sugarcane decomposition.

According to Yuanyuan et al. [38], the reactivity of samples can also be predicted by oxygen adsorption behavior, during the early stage of heating. The absence of mass gain in the related region of TG curve for bagasse sample suggests the formation of more unstable carbonoxygen complexes, which are easily desorbed at relatively low temperatures, increasing the reactivity of this biomass during volatiles release. Therefore, the ignition temperature of samples during combustion is affected by either volatile content or oxygen adsorption behavior.

In order to gain some insight into the interaction between coal and biomass, experimental TG/DTG curves of the blends were compared with the related theoretical curves, which were calculated based on the contribution of each component as described in Eq. 1.

\section{Interaction effect}

Figure 4 shows the comparison between theoretical and experimental TG/DTG curves obtained for the mixtures in three different ratios: 25:75, 50:50, and 75:25. The evidence toward interaction lies in differences observed between theoretical and experimental curves with regard to particular characteristics of a fuel such as ignition and

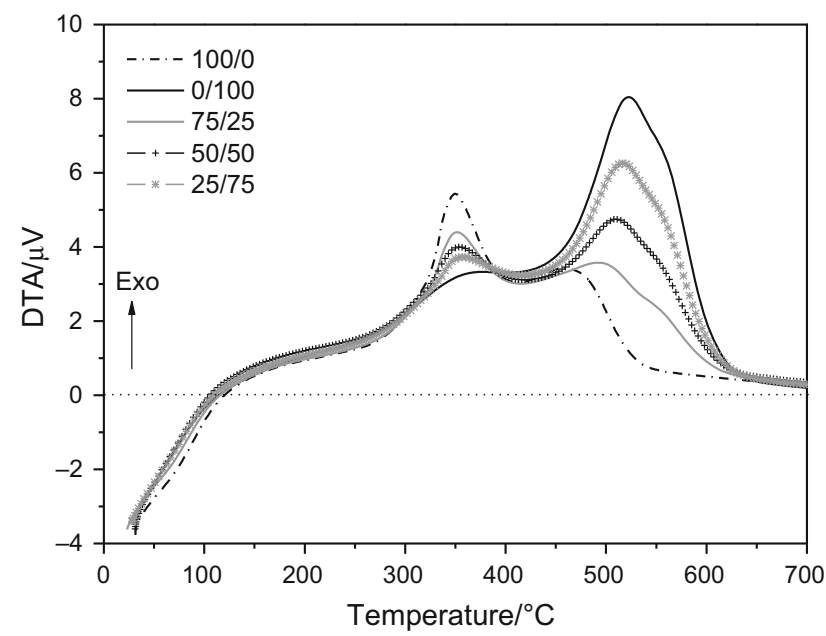

Fig. 3 DTA curves of samples performed under synthetic air and $20{ }^{\circ} \mathrm{C} \min ^{-1}$
Fig. 4 Theoretical and experimental curves of blends with sugarcane bagasse and coal CE 4500, under air atmosphere and heating rate of $20^{\circ} \mathrm{C} \min ^{-1}$. a, c, e TG curves and b, d, $\mathbf{f}$ DTG curves of 25:75, 50:50, and 75:25 blends, respectively

burnout temperatures. Although the theoretical and experimental curves (Fig. 4) are very similar, it is possible to observe slight differences in the ash percentage, temperature of the beginning, and end of decomposition events, as well as the difference in reaction rates (Table 4).

The anticipation of the events related to the decomposition of the coal portion in the mixture is evident mainly in the blend 50:50 under $30{ }^{\circ} \mathrm{C} \mathrm{min}^{-1}$. In addition, the reaction rate related to the DTG inflection at approximately $330{ }^{\circ} \mathrm{C}$ is higher in the experimental curves than in the theoretical curves. Furthermore, another important point is related to ash formation. Although the fuels composition is very heterogeneous, there is a difference in the percentage of residues between TG curves that can be noticed.

Several authors observed interaction between coal and biomass during thermal processes performed in different reactor types $[1,7,12,18,22,41]$. They stated that the effects of synergism may occur due to the high amount of volatile matter present in the biomass given them high reactivity. When the blend of sugarcane bagasse and coal is fed into a reactor, biomass thermal decomposition occurs rapidly. The heat released during biomass devolatilization possibly favors the advance of the thermal decomposition of coal [18].

From our findings, it is possible that synergistic interaction does occur. In this context, the kinetic study might enhance awareness of information about bagasse and coal co-firing process. For that, the activation energy for the thermal decomposition of the individual materials and their blends were evaluated.

\section{Activation energy determination}

The combustion kinetic of sugarcane bagasse, coals, and blends was evaluated at low heating rates $(2.5,5.0$, and $10.0^{\circ} \mathrm{C} \mathrm{min}^{-1}$ ) and high heating rates $(20.0,25.0$, and $30.0{ }^{\circ} \mathrm{C} \mathrm{min}^{-1}$ ) applying two different models. This approach was performed to demonstrate the implications of heating conditions on the activation energy during combustion process.

The employment of low heating rates provides a more controlled environment to perform and evaluate the combustion process, contributing to the application of kinetic model. Nevertheless, we opted to evaluate the kinetics behavior also in high heating rates, to simulate a situation closer to that obtained in practice. More abrupt heating 


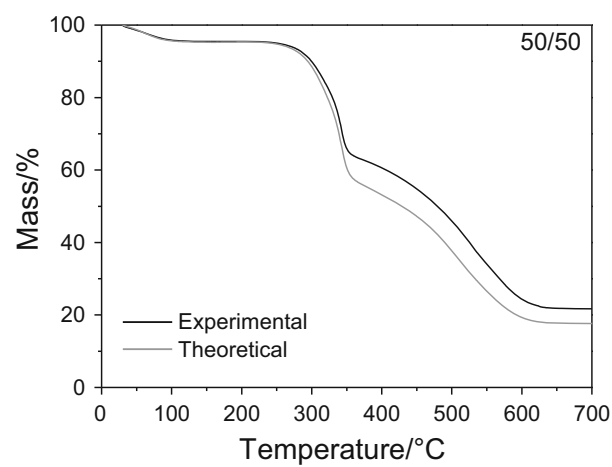

(a)

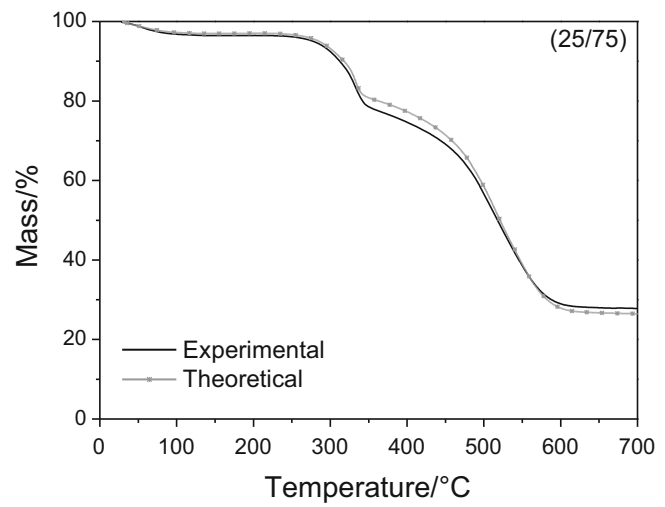

(c)

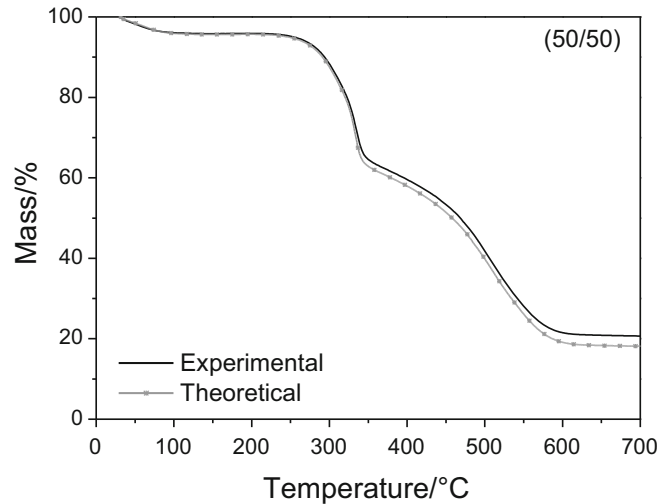

(e)

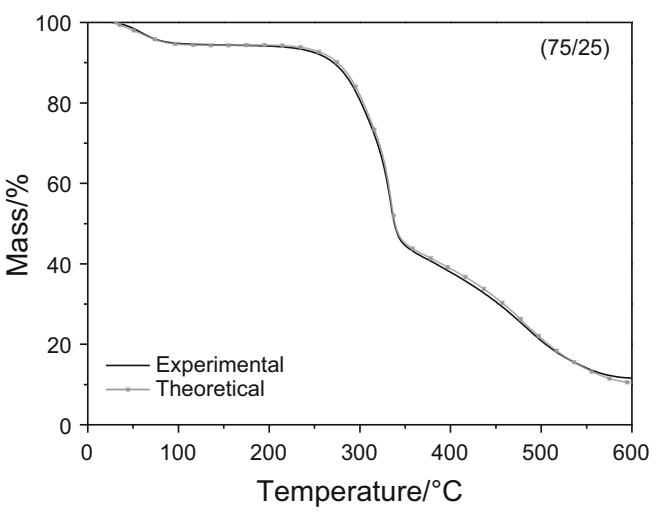

(g)

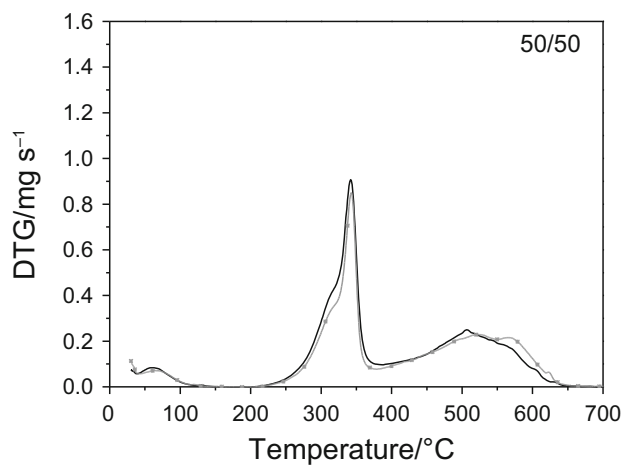

(b)

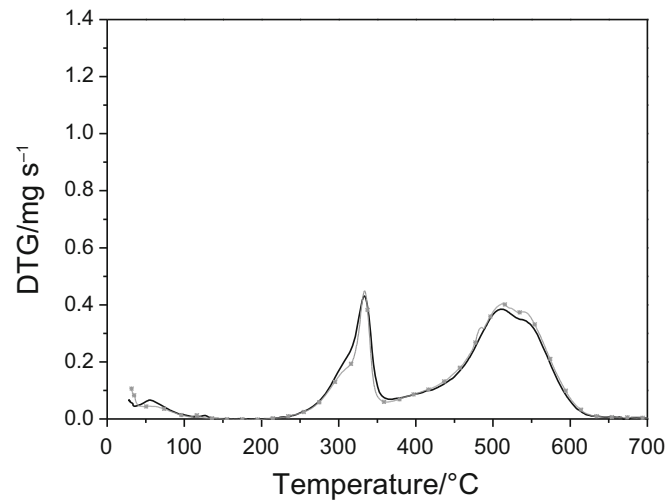

(d)

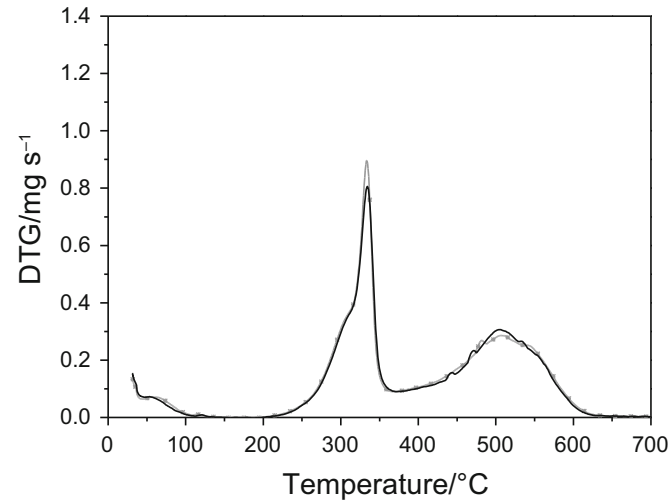

(f)

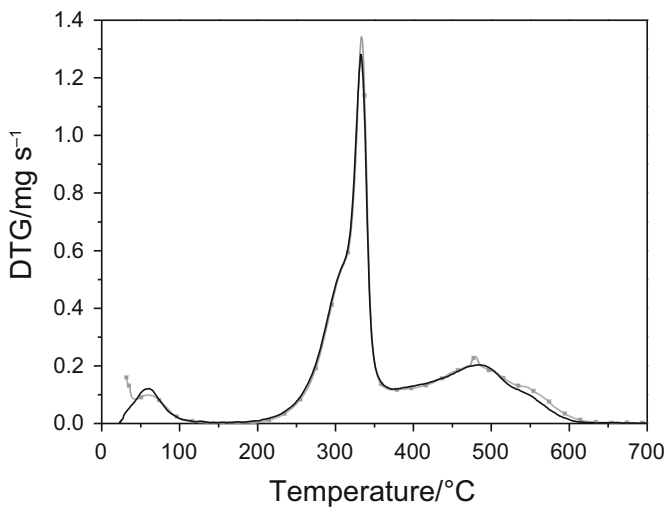

(h) 
Table 4 Comparison between theoretical and experimental values of ash percentage, reaction rate, and the temperature of the beginning and end of decomposition events

\begin{tabular}{|c|c|c|c|c|c|c|}
\hline \multirow[t]{2}{*}{ Parameters } & \multicolumn{2}{|l|}{$25: 75$} & \multicolumn{2}{|l|}{$50: 50$} & \multicolumn{2}{|l|}{$75: 25$} \\
\hline & Theoretical & Experimental & Theoretical & Experimental & Theoretical & Experimental \\
\hline $\mathrm{T} 1 /{ }^{\circ} \mathrm{C}$ & 221.1 & 221.1 & 200.0 & 200.0 & 183.9 & 183.9 \\
\hline $\mathrm{T} 2 /{ }^{\circ} \mathrm{C}$ & 315.0 & 315.0 & 315.0 & 315.0 & 313.9 & 313.9 \\
\hline $\mathrm{T} 3 /{ }^{\circ} \mathrm{C}$ & 333.9 & 333.9 & 333.9 & 333.9 & 333.9 & 333.9 \\
\hline $\mathrm{T} 4 /{ }^{\circ} \mathrm{C}$ & 357.5 & 368.3 & 371.9 & 371.9 & 374.1 & 374.1 \\
\hline $\mathrm{T} 5 /{ }^{\circ} \mathrm{C}$ & 511.4 & 511.2 & 507.0 & 507.0 & 478.4 & 478.4 \\
\hline $\mathrm{T} 6 /{ }^{\circ} \mathrm{C}$ & 540.1 & 540.2 & 534.5 & 543.9 & 543.9 & 551.2 \\
\hline $\mathrm{T} 7 /{ }^{\circ} \mathrm{C}$ & 652.4 & 652.4 & 639.8 & 639.8 & 629.0 & 616.3 \\
\hline DTG1/mg s${ }^{-1}$ & 0.18 & 0.23 & 0.39 & 0.39 & 0.6 & 0.6 \\
\hline DTG $2 / \mathrm{mg} \mathrm{s}^{-1}$ & 0.44 & 0.42 & 0.79 & 0.89 & 1.34 & 1.27 \\
\hline DTG3/mg s ${ }^{-1}$ & 0.40 & 0.38 & 0.28 & 0.31 & 0.21 & 0.21 \\
\hline DTG4/mg s ${ }^{-1}$ & 0.38 & 0.34 & 0.31 & 0.28 & 0.13 & 0.09 \\
\hline $\mathrm{Ash} / \%$ & 26.6 & 27.9 & 18.2 & 21.0 & 10.8 & 12.2 \\
\hline
\end{tabular}

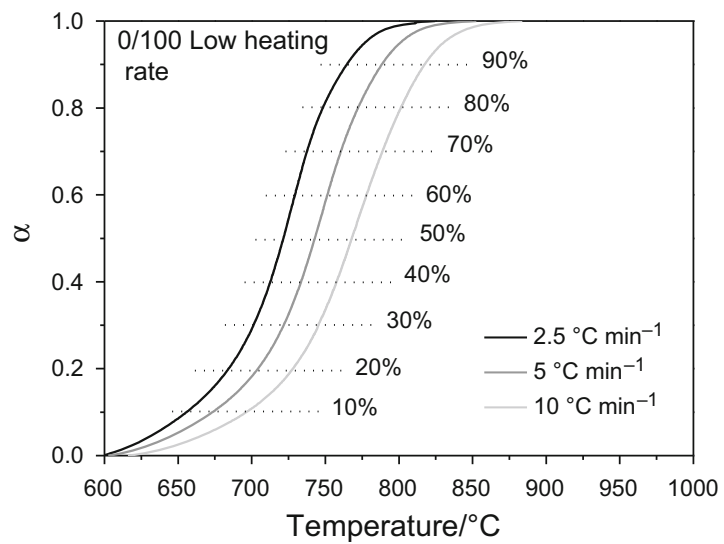

(a)

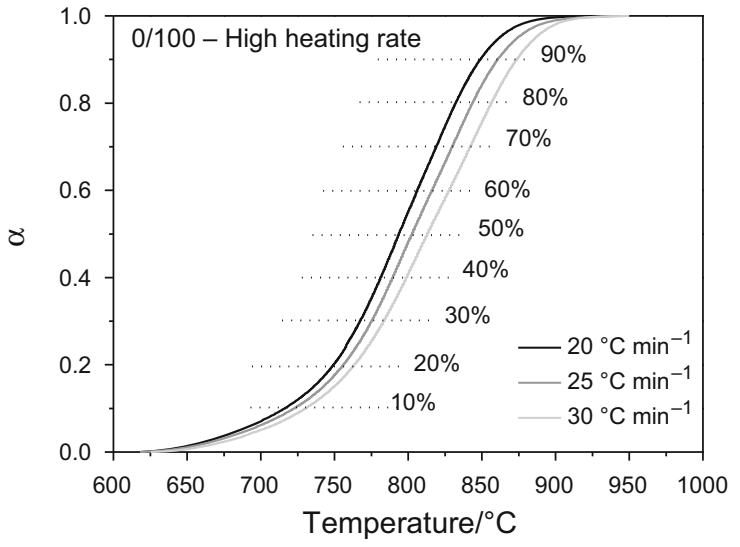

(b)

Fig. 5 Thermal conversion curves of CE4500 under a low heating rate and $\mathbf{b}$ high heating rate

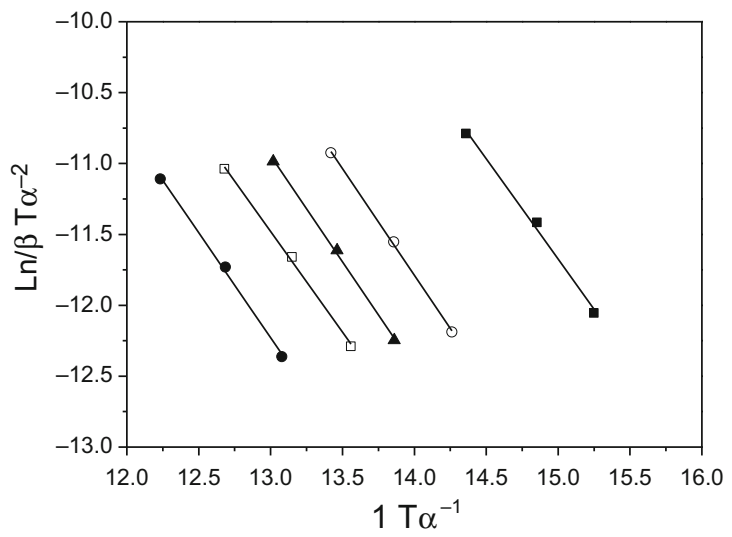

(a)

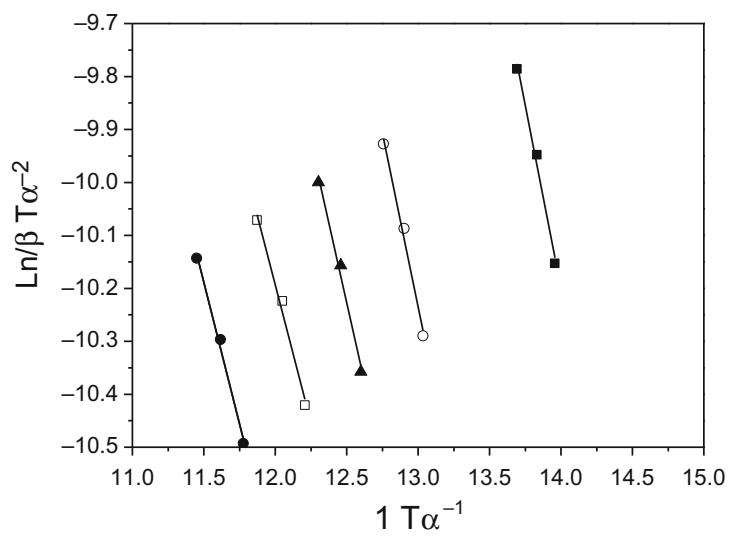

(b)

Fig. 6 Arrhenius plot $-1^{\circ}$ step of CE 4500 decomposition under a low heating rate and $\mathbf{b}$ high heating rate 


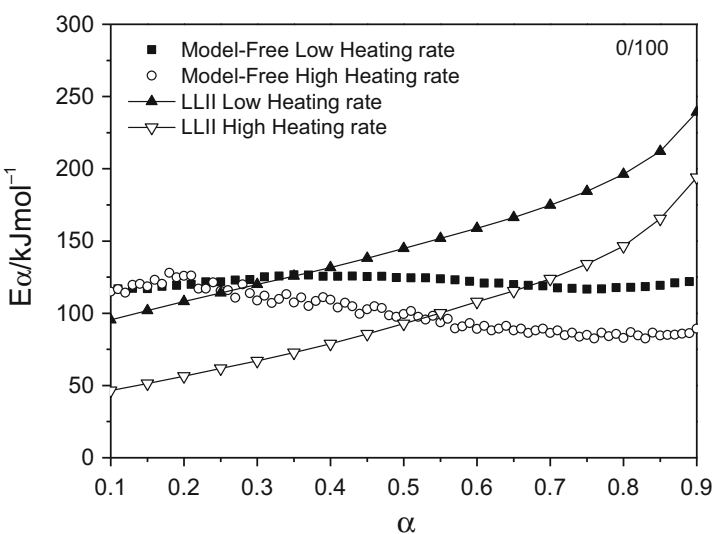

(a)

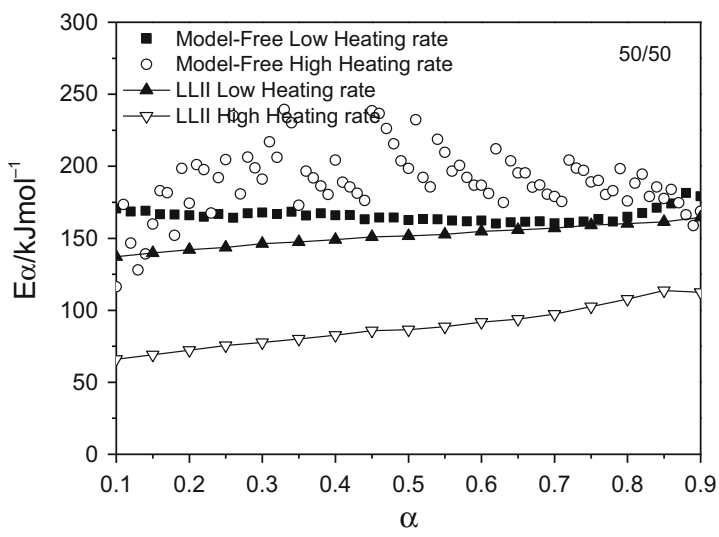

(c)

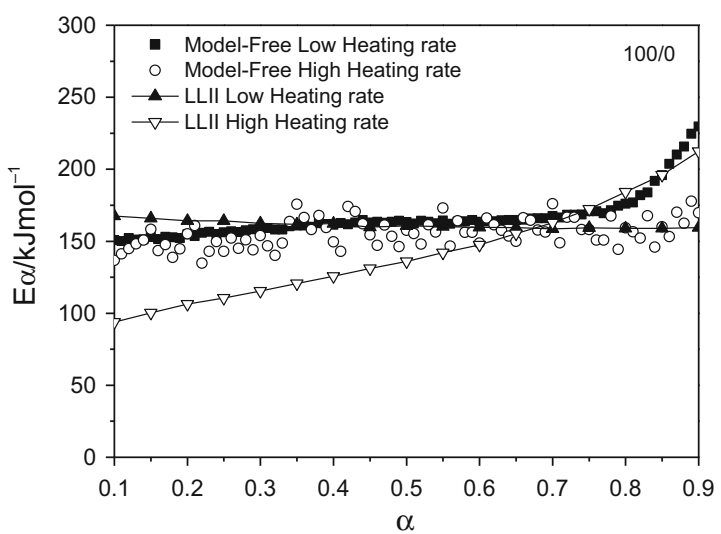

(e)

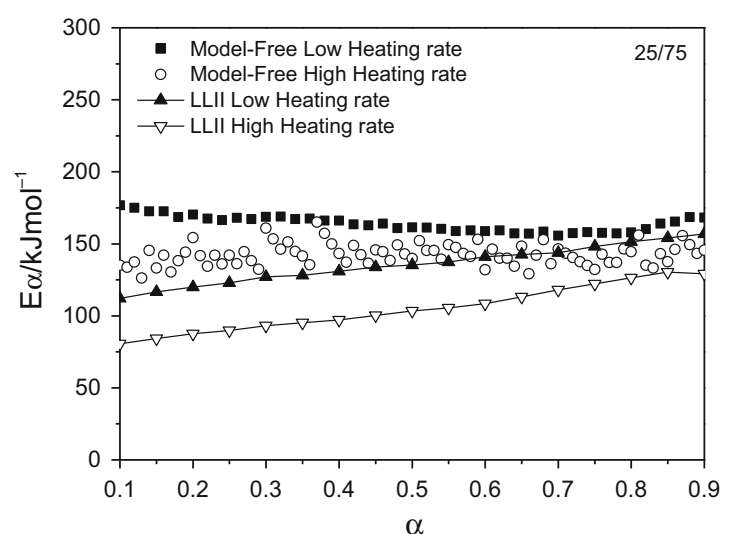

(b)

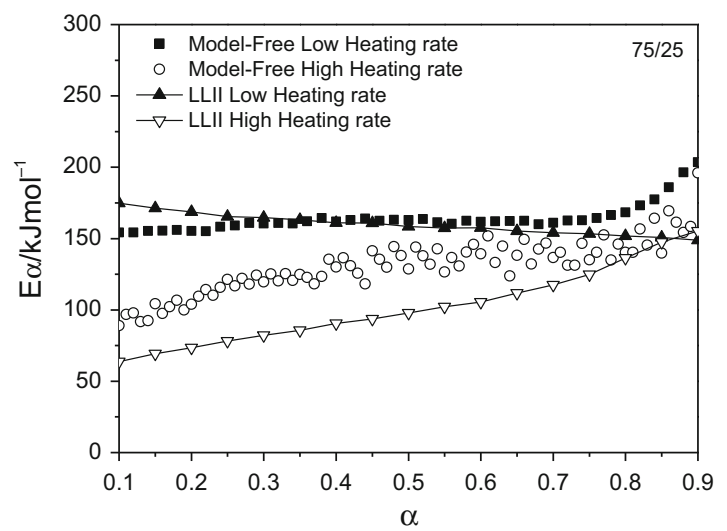

(d)

Fig. $7 E_{\alpha}$ versus $\alpha$ profiles obtained for a 0:100, b 25:75, c 50:50, d 75:25, and e 100:0

conditions were not applied since they might cause diffusional limitations to the samples.

Given the considerations above, conversion curves of coal (0:100) regarding the $1^{\circ}$ step of decomposition under low and high heating rates are shown in Fig. 5.

The conversion is displaced to higher temperatures as the heating rate was increased. According to Buratti et al.
[42], at high heating rates, the heat transfer inside the particles is less effective, leading to a more intense the mass loss rate and rapid decomposition.

Figure 6 illustrates the results obtained for coal (0:100). It is possible to verify a good fit of the coal decomposition data in model free by means of the linear and parallel Arrhenius plots (isoconversional plots). 
Table 5 Average values and standard deviation of $E_{\alpha}$ at low and high heating rate of the blends 0:100, 100:0, 75:25, 50:50, and 25:75

\begin{tabular}{|c|c|c|c|c|c|c|c|c|}
\hline \multirow[t]{3}{*}{ Bagasse/coal ratio } & \multicolumn{4}{|c|}{ Low heating rate } & \multicolumn{4}{|c|}{ High heating rate } \\
\hline & \multicolumn{2}{|c|}{ Average $/ \mathrm{kJ} \mathrm{mol}^{-1}$} & \multicolumn{2}{|c|}{ Standard deviation $/ \mathrm{kJ} \mathrm{mol}^{-1}$} & \multicolumn{2}{|c|}{ Average $/ \mathrm{kJ} \mathrm{mol}^{-1}$} & \multicolumn{2}{|c|}{ Standard deviation $/ \mathrm{kJ} \mathrm{mol}^{-1}$} \\
\hline & Model free & LLII & Model free & LLII & Model free & LLII & Model free & LLII \\
\hline $0: 100$ & 121.38 & 154.59 & 3.23 & 51.82 & 100.60 & 103.87 & 13.70 & 52.27 \\
\hline 100:0 & 166.39 & 161.66 & 15.61 & 3.17 & 155.49 & 144.15 & 9.91 & 42.10 \\
\hline $75: 25$ & 163.97 & 160.21 & 9.50 & 9.41 & 130.75 & 102.52 & 19.01 & 30.38 \\
\hline $50: 50$ & 165.59 & 151.43 & 4.47 & 9.40 & 189.74 & 87.51 & 22.63 & 15.50 \\
\hline $25: 75$ & 163.63 & 135.14 & 5.34 & 14.94 & 142.58 & 104.40 & 7.44 & 16.91 \\
\hline
\end{tabular}

The first step of decomposition occurs within $70-75 \%$ of heat release due to the devolatilization [43]. The activation energy values and the profile of $E_{\alpha}$ versus $\alpha$ curves indicate the sensitivity of the reaction rate to the temperature [39]. Furthermore, these curves show the mechanism along all the degradation process.

As can be seen in Fig. 7, the results obtained by modelfree fitting show similar values of initial $E_{\alpha}$ at high and at low heating rates (around $120 \mathrm{~kJ} \mathrm{~mol}^{-1}$ to $0: 100$ and $150 \mathrm{~kJ} \mathrm{~mol}^{-1}$ to $\left.100: 0\right)$ for the neat samples (100:0 and 0:100). However, as the conversion advances, the $E_{\alpha}$ values obtained under low heating rate present higher values than those obtained under high heating rate, but to 50:50 blend. When sugarcane bagasse and coal are blended, the $E_{\alpha}$ initial values are about $75 \mathrm{~kJ} \mathrm{~mol}^{-1}$ higher under low heating rate than under high heating rate. It can be an indicative of an interaction effect of the blended materials.

It is interesting to note that the blend with the highest proportion of bagasse presented a behavior very similar to neat bagasse with regard to the increasing $E_{\alpha}$ values at the end of combustion process (from 0.8 of conversion).

The results obtained by LLII model fitting show the tendency of lower $E_{\alpha}$ values under high heating rate conditions. The initial $E_{\alpha}$ values for the neat materials show different values, i.e., the initial $E_{\alpha}$ was 50 and $100 \mathrm{~kJ} \mathrm{~mol}^{-1}$ for coal and bagasse, respectively, under high heating rate, and 100 and $175 \mathrm{~kJ} \mathrm{~mol}^{-1}$ for coal and bagasse, respectively, under low heating rate. However, it is possible to observe that the curves obtained to 75:25 and 100:0 present an intersection of the profiles that occurs around conversions of 60 and $80 \%$ to $100: 0$ and $75: 25$ curves, respectively. These findings may be related to the different kinetic models employed. The literature states that the growing dependence between $E_{\alpha}$ and the conversion degree indicates parallel competitive reaction occurrence [10]. However, the intersection may be an indicative that the process changed under those conditions was dominated by reactions with decreasingly $E_{\alpha}$.
In general, the adopted model and model fitting have great influence in the $E_{\alpha}$ values as well as in the $E_{\alpha}$ versus $\alpha$ profile [44]. However, if the difference appears not only in the values but also in the $E_{\alpha}$ profile, it indicates a change in the mechanism of the reactions which govern the decomposition process of biomass samples.

Comparing both models regarding heating rate, $E_{\alpha}$ versus $\alpha$ profiles present a similar behavior for all samples-higher $E_{\alpha}$ at low heating rate from 0.1 up to 0.9 of conversion, except for 50:50 obtained by model-free in which the profile is more unstable.

Table 5 shows the $E_{\alpha}$ and standard deviation values related to the decomposition of coal, sugarcane bagasse, and blends, between 0.1 and 0.9 of conversion obtained by model-free and LLII fitting.

As given in Table 5, all the $E_{\alpha}$ average values obtained are lower at high heating rate except for the 50:50 blend. From model-free results, the blend 50:50 presented the highest $E_{\alpha}$ average value $\left(189.74 \mathrm{~kJ} \mathrm{~mol}^{-1}\right)$, more unstable profile and the highest standard deviation $\left(22.63 \mathrm{~kJ} \mathrm{~mol}^{-1}\right)$, demonstrating the complex reaction mechanism. The $E_{\alpha}$ values increase as follows: $0: 100<75: 25<25: 75<100: 0<50: 50$ at high heating rate.

On the other hand, for 50:50 from LLII model it was obtained the lowest $E_{\alpha}$ average value (87.51), a stable profile and a low standard deviation $\left(15.50 \mathrm{~kJ} \mathrm{~mol}^{-1}\right)$ and The $E_{\alpha}$ values increase as follows: 50:50<0:100<75:25<25:75<100:0. Both models present a high complexity process to the $50: 50$ blend, but the results are obtained in the opposite way. This discrepancy may be related to the methodology applied for the activation energy determination. Although the LLII method presents more stable $E_{\alpha}$ profiles (Fig. 7), the standard deviation is higher.

The difference in $E_{\alpha}$ values appears and gets bigger as the heating rate increases; hence, it is important to consider the scale of application in which the heating rate can reach $10^{5}{ }^{\circ} \mathrm{C} \mathrm{min}{ }^{-1}$. Given the above considerations, the 
interaction between fuels may cause higher effects in a real scale of co-firing.

In conclusion, if there were no interactions, the 100:0 profile would be the most complex due to the highest volatile matter content. Nevertheless, the most complex profile is obtained to 50:50 ratio, confirmed by the discrepant $\mathrm{E}_{\alpha}$ values achieved at high heating rates.

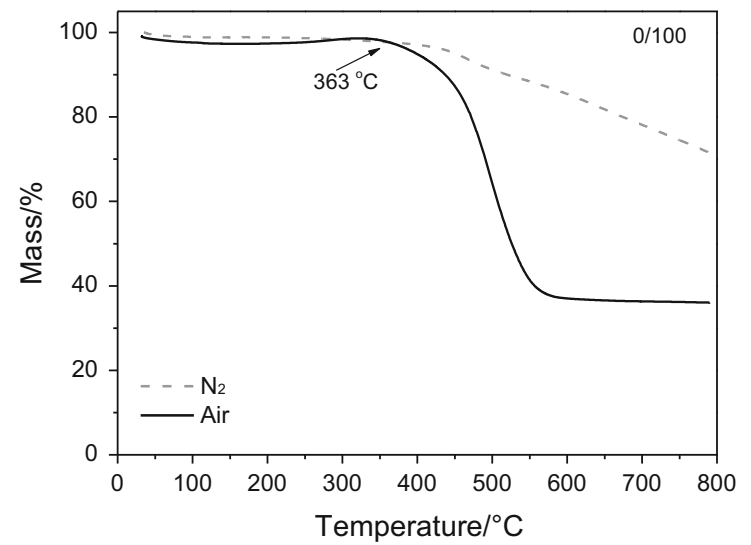

(a)

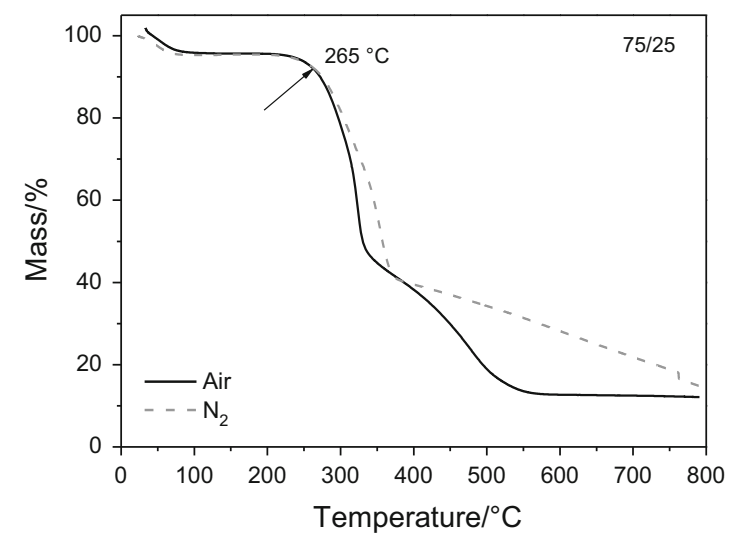

(c)

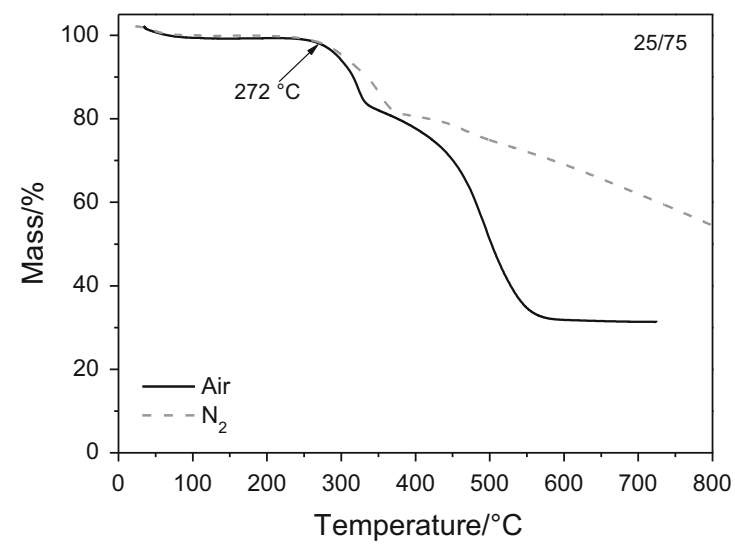

(e)

\section{Ignition temperature determination}

The ignition temperatures of sugarcane bagasse, coal, and blends have been determined from the TGA applying the deviation method proposed by Tognotti [26]. The TGA distribution for all materials under air and $\mathrm{N}_{2}$ atmospheres is presented in Fig. 8.

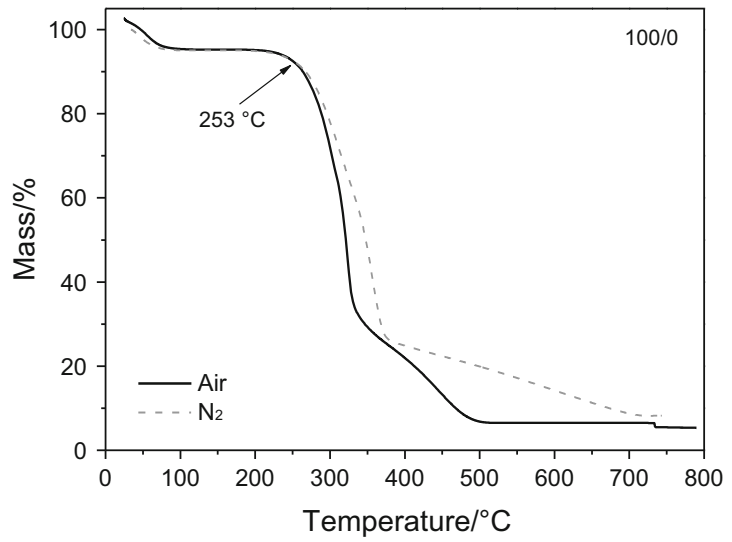

(b)

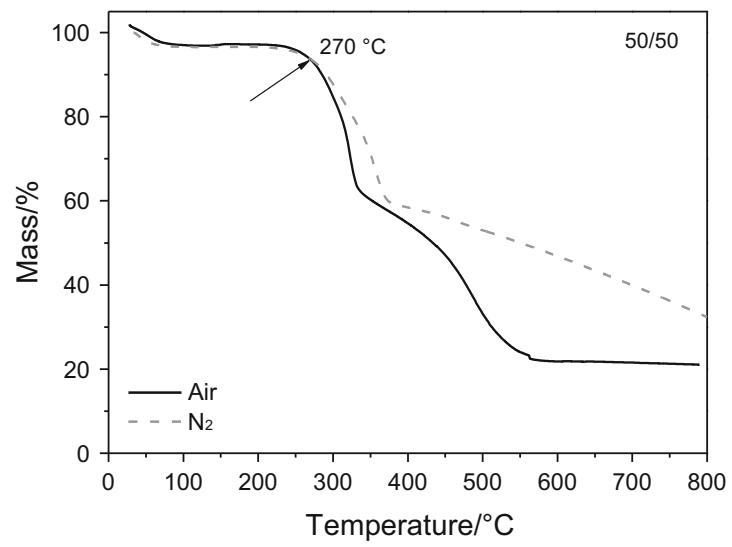

(d)

Fig. 8 TG curves under air and $\mathrm{N}_{2}$ of a 0:100, b 100:0, c 75:25, d 50:50, and e 25:75 for ignition temperature determination (bagasse/coal) 
Neat CE 4500 presents a higher ignition temperature $\left(363{ }^{\circ} \mathrm{C}\right)$ than the neat sugarcane bagasse $\left(263{ }^{\circ} \mathrm{C}\right)$, which is a reflection of the diversity of samples in either the chemical composition or the physical characteristics. As presented in Table 1 and Fig. 1, sugarcane bagasse is composed by a high percentage of volatile matter with a fibrous and porous structure. Such characteristics enable the easy ignition and burnout of this biomass in relation to coal.

The ignition temperatures obtained for the blends were $272{ }^{\circ} \mathrm{C}$ for $25: 75,270{ }^{\circ} \mathrm{C}$ for $50: 50$, and $265{ }^{\circ} \mathrm{C}$ for $75: 25$. Thus, the ignition temperature decreases as the ratio of sugarcane bagasse increases in the blend. In other words, the ignition of sugarcane bagasse (high volatile content) may enhance the ignition of CE 4500. According to Faúndez et al. [45], when fuels with different volatile content are blended, the ignition of the higher volatile content fuel may favor the ignition of the lower volatile content fuel.

The same behavior was observed by Riaza et al. [46] blending a coal with olive residue. According to the authors, the decreasing ignition temperature is proportional to the amount of the biomass in the blend and this effect is more pronounced in high rank coals. They also stated that the ignitions properties are different when the materials are burned individually or as blends.

Therefore, the increase in the ignition temperature with the increase in coal ratio may be understood as an interaction effect. The relation between composition (in terms of volatile matter and oxygen percentage) and the contribution of bagasse devolatiquerlization on the synergism effect was only confirmed by the thermal decomposition, theoretical versus experimental and ignition temperature determination. Nevertheless, the presence of the bagasse did not allow to lower activation energy during the blends devolatilization process.

\section{Conclusions}

The interaction effect evaluated in this study was related to the interference of the bagasse volatile matter content in the coal thermal decomposition (activation energy and ignition temperature) when blended. We investigated the interaction between sugarcane bagasse and coal during cofiring using different ratios of blend. The thermogravimetric evaluation revealed that the combustion process of sugarcane bagasse is more intense than coal due to its higher volatile matter content.

The comparison between theoretical and experimental TG/DTG curves showed a temperature anticipation of the events related to the decomposition of the coal portion in the mixture in experimental condition, mainly in the blend of 50:50 and, the reaction rates were higher in the experimental curves than in the theoretical curves. Furthermore, it was observed differences in the percentage of residues, indicating an influence on ash formation when the samples are blended.

The kinetic data suggested that the interaction between both materials may occur and improve the burnout of the blend in relation to the pure coal firing due to the contribution of sugarcane bagasse volatile matter.

In conclusion, the ignition of the high volatile sugarcane bagasse was shown to enhance the ignition of coal since the ignition temperature decreases as the ratio of sugarcane bagasse increases. When the materials are blended, there is a change in the reaction mechanism and the reactions involved in the process turn more complex, as indicated by the kinetic data.

Acknowledgements The authors would like to acknowledge FAPESP Research Foundation of São Paulo State (Project 2011/00183-2) and Coordenacão de Aperfeiçoamento de Pessoal de Nivel Superior (CAPES), for the financial support provided to this research.

\section{References}

1. Kazanç F, Khatami R, Crnkovic PM, Levendis Y. Emissions of $\mathrm{NO}_{x}$ from coals of various ranks, bagasse, and coal-bagasse blends burning in $\mathrm{O}_{2} / \mathrm{N}_{2}$ and $\mathrm{O}_{2} / \mathrm{CO}_{2}$ environments. Energy Fuel. 2011;25(7):2850-61.

2. Gao C, Vejahaty F, Katalambula H, Gupta R. Co-gasification of biomass with coal and oil sand coke in a drop tube furnace. Energy Fuel. 2010;24:232-40.

3. Rasul MG, Rudolph V. Fluidized bed combustion of Australian bagasse. Fuel. 2000;79:123-30.

4. Woytiuk K, Sanscartier D, Amichev BY, Campbell W, Rees KV. Modeling and analysis: life-cycle assessment of torrefied coppice willow co-firing with lignite coal in an existing pulverized coal boiler. Biofuels Bioprod Bioref. 2017;11(5):830-46.

5. FAO-Food and Agriculture Organization of the United Nations. http://www.fao.org/docrep/003/w3647e/w3647e03.htm. Accessed 5 May 2016.

6. Unica-Brazilian Sugarcane Industry Association: http://www. unicadata.com.br/listagem.php?idMn=88. Accessed 5 May 2016.

7. BEN 2015 Report. https://ben.epe.gov.br/downloads/Relatorio_ Final_BEN_2015.pdf. Accessed 5 May 2016.

8. Munir S, Daood SS, Nimmo W, Cunliffe AM, Gibbs BM. Thermal analysis and devolatilization kinetics of cotton stalk, sugar cane bagasse and shea meal under nitrogen and air atmospheres. Bioresour Technol. 2009;100:1413-8.

9. Shen DK, Gu S, Luo KH, Bridgwater AV, Fang MX. Kinetic study on thermal decomposition of woods in oxidative environment. Fuel. 2009;88:1024-39.

10. Torquato LM, Braz CEM, Ribeiro CA, Capela JMV, Crespi MS. Kinetic study of the co-firing of bagasse-sludge blends. J Therm Anal Calorim. 2015;21:499-507.

11. Al-Qayim K, Nimmo W, Hughes K, Pourkashanian M. Kinetic parameters of the intrinsic reactivity of woody biomass and coal chars via thermogravimetric analysis. Fuel. 2017;210:811-25.

12. Yuzbasi NS, Seçuk N. Air and oxy-fuel combustion characteristics of biomass/lignite blends in TGA-FTIR. Fuel Process Technol. 2011;92:1101-8. 
13. Mureddu M, Dessì F, Orsini A, Ferrara F, Pettinau A. Air- and oxygen-blown characterization of coal and biomass by thermogravimetric analysis. Fuel. 2018;212:626-37.

14. Vyazovkin S, Burnham AK, Criado JM, Pérez-Maqueda LA, Popescu C, Sbirrazzuoli N. ICTAC kinetics committee recommendations for performing kinetic computations on thermal analysis data. Thermochim Acta. 2011;520:1-19.

15. El-Sayed SA, Mostafa ME. Kinetic parameters determination of biomass pyrolysis fuels using TGA and DTA techniques. Waste Biomass Valor. 2015;6:401-15.

16. Alwani MS, Abdul Khalil HPS, Sulaiman O, Islam MN, Dungani R. An approach to using agricultural waste fibres in biocomposites application: thermogravimetric analysis and activation energy study. BioResources. 2014;9(1):218-30.

17. Fermoso J, Gil M, Pevida C, Pis J, Rubiera F. Kinetic models comparison for non-isothermal steam gasification of coal-biomass blend chars. Chem Eng J. 2010;161:276-84.

18. Edreis EMA, Luo G, Li A, Chao C, Hua H, Zhang S, Gui B, Xiao L, Xua K, Zhang P, Yao H. $\mathrm{CO}_{2}$ co-gasification of lower sulphur petroleum coke and sugar cane bagasse via TG-FTIR analysis technique. Bioresour Technol. 2013;136:595-603.

19. Bragato M, Joshi K, Carlson JB, Tenório JAS, Levendis YA. Combustion of coal, bagasse and blends thereof part II: speciation of PAH emissions. Fuel. 2012;96:51-8.

20. Krerkkaiwan S, Fushimi C, Yamamoto H, Tsutsumi A, Kuchonthara P. Influences of heating rate during coal char preparation and AAEMs on volatile-char interaction with different sources of biomass volatile. Fuel Process Technol. 2014;119:10-8.

21. Kastanaki E, Vamvuka D. A comparative reactivity and kinetic study on the combustion of coal-biomass char blends. Fuel. 2006;85:1186-93.

22. Idris SS, Rahman NA, Ismail K, Alias AB, Rashid ZA, Aris MJ. Investigation on thermochemical behaviour of low rank Malaysian coal, oil palm biomass and their blends during pyrolysis via thermogravimetric analysis (TGA). Bioresour Technol. 2010;101:4584-92.

23. Sahu SG, Chakraborty N, Sarkar P. Coal biomass co-combustion: an overview. Renew Sust Energy Rev. 2014;39:575-86.

24. Demirbas A. Sustainable cofiring of biomass with coal. Energy Convers Manage. 2003;44:1465-79.

25. Ávila I, Crnkovic PM, Luna CMR, Milioli FE. Use of a fluidized bed combustor and thermogravimetric analyzer for the study of coal ignition temperature. Appl Therm Eng. 2017;114:984-92.

26. Tognotti L, Malotti A, Petarca L, Zanelli S. Measurement of ignition temperature of coal particles using a thermogravimetric technique. Combust Sci Technol. 1985;44:15-28.

27. Vyazovkin S, Wight CA. Model-free and model-fitting approaches to kinetic analysis of isothermal and nonisothermal data. Thermochim Acta. 1999;340:53-68.

28. Wanjun T, Donghua C. An integral method to determine variation in activation energy with extent of conversion. Thermochim Acta. 2005;433(1-2):72-6.
29. Da Silva DR, Crespi MS, Ribeiro CA, Capela JMV. Thermal decomposition kinetics of sugarcane mills wastes. J Therm Anal Calorim. 2017. https://doi.org/10.1007/s10973-017-6270-z.

30. Yurdakul S. Determination of co-combustion properties and thermal kinetics of poultry litter/coal blends using thermogravimetry. Renew Energy. 2016;89:215-23.

31. Quensanga A, Picard C. Thermal degradation of sugar cane bagasse. Thermochim Acta. 1988;125:87-9.

32. Aiman S, Stubington JF. The pyrolysis kinetics of bagasse at low heating rates. Biomass Bioenergy. 1993;5(2):113-20.

33. Byrne CE, Nagle DC. Carbonization of wood for advanced materials applications. Carbon. 1996;35(2):259-66.

34. Yang H, Yan R, Chen H, Lee DH, Zheng C. Characteristics of hemicelluloses, cellulose and lignin pyrolysis. Fuel. 2007;86:1781-8.

35. Guimarães JI, Frollini E, Silva CG, Wypych F, Satyanarayana KG. Characterization of banana, sugarcane bagasse and sponge gourd fibers of Brazil. Ind Crop Prod. 2009;30:407-15.

36. Avila T, Wu E, Lester E. Estimating the spontaneous combustion potential of coals using thermogravimetric analysis. Energy Fuel. 2014;28:1765-73.

37. Li B, Chen G, Zhang H, Sheng CD. Development of nonisothermal TGA-DSC for kinetics analysis of low temperature coal oxidation prior to ignition. Fuel. 2014;118:385-91.

38. Yuanyuan Z, Yanxia G, Fangqin C, Kezhou Y, Yan C. Investigation of combustion characteristics and kinetics of coal gangue with different feedstock properties by thermogravimetric analysis. Thermochim Acta. 2015;614:137-48.

39. Fang X, Jia L, Yin IA. Weighted average global process model based on two-stage kinetic scheme for biomass combustion. Biomass Bioenergy. 2013;48:43-5.

40. Da Silva DR, Crespi MS, Crnkovic PCGM, Ribeiro CA. Pyrolysis, combustion and oxy-combustion studies of sugarcane industry wastes and its blends. $\mathrm{J}$ Therm Anal Calorim. 2015;121(1):309-18.

41. Nimmo W, Daood SS, Gibbs BM. The effect of $\mathrm{O}_{2}$ enrichment on $\mathrm{NO}_{x}$ formation in biomass co-fired pulverized coal combustion. Fuel. 2010;89(10):2945-52.

42. Buratti C, Barbanera M, Bartocci P, Fantozzi F. Thermogravimetric analysis of the behavior of sub-bituminous coal and cellulosic ethanol residue during co-combustion. Bioresour Technol. 2015;186:154-62.

43. Motaunga TE, Anandjiwala RD. Effect of alkali and acid treatment on thermal degradation kinetics of sugar cane bagasse. Ind Crop Prod. 2015;74:472-7.

44. Brown ME, Gallagher PK. Handbook of thermal analysis and calorimetry, recent advances, techniques and applications, vol. 5. Amsterdam: Elsevier; 2008.

45. Faúndez J, Arias B, Rubiera F, Arenillas A, García X, Gordon $\mathrm{AL}$, Pis JJ. Ignition characteristics of coal blends in an entrained flow furnace. Fuel. 2007;86:2076-80.

46. Riaza J, Álvarez L, Gil MV, Pevida C, Pis JJ, Rubiera F. Ignition and NO emissions of coal and biomass blends under different oxy-fuel atmospheres. Energy Proced. 2013;37:1405-12. 